\title{
Developing a Community-Based Research Project Proposal to Build Public Health Educator Capacity: A Graduate Student Perspective.
}

\author{
Alexander J. Baukus \\ Thomas Jefferson University
}

Follow this and additional works at: https://jdc.jefferson.edu/student_papers

Part of the Public Health Commons

Let us know how access to this document benefits you

\section{Recommended Citation}

Baukus, Alexander J., "Developing a Community-Based Research Project Proposal to Build Public Health Educator Capacity: A Graduate Student Perspective." (2019). Student Papers \& Posters. Paper 45.

https://jdc.jefferson.edu/student_papers/45

This Article is brought to you for free and open access by the Jefferson Digital Commons. The Jefferson Digital Commons is a service of Thomas Jefferson University's Center for Teaching and Learning (CTL). The Commons is a showcase for Jefferson books and journals, peer-reviewed scholarly publications, unique historical collections from the University archives, and teaching tools. The Jefferson Digital Commons allows researchers and interested readers anywhere in the world to learn about and keep up to date with Jefferson scholarship. This article has been accepted for inclusion in Student Papers \& Posters by an authorized administrator of the Jefferson Digital Commons. For more information, please contact: JeffersonDigitalCommons@jefferson.edu. 


\section{Health Promotion Practice}

\section{Manuscript Title: Developing a Community-Based Research Project Proposal to Build Public Health Educator Capacity: A Graduate Student Perspective}

\begin{tabular}{|c|l|}
\hline Journal: & Health Promotion Practice \\
\hline Manuscript ID & HPP-19-0253.R2 \\
\hline Keywords: & $\begin{array}{l}\text { Community-Based Participatory Research < Health Research, College / } \\
\text { Community Partnerships < University / College Health, Program Planning } \\
\text { and Evaluation }\end{array}$ \\
\hline Abstract: & $\begin{array}{l}\text { This article is the author's first-person perspective of completing an } \\
\text { applied practice experience (APE) at an accredited public health } \\
\text { program. Graduate-level public health students in the United States are } \\
\text { mandated by the Council on Education for Public Health to complete this } \\
\text { supervised field experience to apply knowledge and concepts to real- } \\
\text { world public health practice. For his APE, the author worked with a } \\
\text { faculty advisor and two community groups to facilitate and submit a } \\
\text { community-based participatory research grant proposal. This article } \\
\text { discusses the author's experiences before, during, and after the APE. The } \\
\text { author outlines challenges and success of working on this applied } \\
\text { project. The article concludes with implications for public health } \\
\text { education specialists regarding experiential learning and applied practice } \\
\text { experiences for graduate students. }\end{array}$ \\
\hline
\end{tabular}

\section{SCHOLARONE Manuscripts}


As part of graduate-level study in public health in the United States, students are mandated by the Council on Education for Public Health (CEPH) to complete an Applied Practice Experience (APE) (Council on Education for Public Health, 2016). The purpose of this supervised field experience in the public health curriculum is for students to utilize the knowledge and concepts learned from public health study and course work in an applied setting, and refine interpersonal professional skills within the context of public health practice. Dependent on their program, students are able to select from a variety of different sites suited to their interests ranging from internships with the local public health department to statistical

11 processing. Regardless of his or her site, each student must complete a total of 120 hours in an 12 approved practice setting.

13 This article provides a student perspective after completing an APE at an accredited

14 public health program where I had to opportunity to collaborate with both independent

15 community groups and a faculty member in a community-based research project proposal. The

16 purpose of this article is for health promotion educators and practitioners to see such an

17 experience from a student perspective. It is my hope that through this article I can highlight

18 aspects of my experience that were beneficial and effective learning tools, as well as provide

19 examples of challenges I faced with the intent of providing educators with ideas to incorporate

20 into similar student experiences.

\section{My Experience Before the APE}

As I progressed through my MPH program at the Thomas Jefferson University, Jefferson,

23 I had my eye on participating in a unique APE. With assistance from my academic advisor, I was 
24 connected with public health professor Dr. Amy Henderson Riley, who graciously invited me to

25 learn more about several ongoing projects she was a part of and to explore if I was interested in

26 becoming involved as a graduate student. Having these options to choose from was valuable to

27 me, as I was able to identify a project where I could match my interest and tailor my own

28 learning experience to my career goals and interests.

During the site selection process for my APE, I first attended a joint university-

community information session called Community Driven Research Day (CDRD). This meeting

31 was designed to link community groups with research institutions, and provided avenues of

32 funding for programs through grants. Following the meeting, a request for proposals was issued.

33 My mentor, Dr. Riley had participated in a previous CDRD event and had met with a local

34 community group called the Creative Resilience Collective (CRC). This group had a vision of

35 devising a program with the goal of engaging young refugee and immigrant teens through art in

36 order to explore and identify spaces where they feel safe and experience mental health relief.

37 CRC was interested in partnering with our academic institution for development of the proposal

38 for the grant to fund the program.

39 This collaboration between the community group CRC and Thomas Jefferson University

40 is an example of Community Based Participatory Research (CBPR). Within the realm of public

41 health, CBPR is an important paradigm. Israel et al. (1998) defined CBPR as "... a collaborative

42 approach to research that equitably involves, for example, community members, organizational

43 representatives, and researchers in all aspects of the research process" (p. 177). CBPR was not

44 available to me as a stand-alone course as part of the MPH course offerings in my program, but

45 the APE allowed me to experience it in a real world setting. In January of 2019, I formally

46 signed on to work on this CBPR collaboration for my APE. This involved agreeing to goals and 
47 objectives that I co-wrote with my preceptors, which were then approved by our program's APE

48 coordinator. These included:

1. Gain experience building a budget for a public health project;

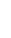

(Table 1), as described by my program’s APE Goals \& Objectives agreement.

2. Collaborate with community partners to design and guide a public health project from conception of ideas to a tangible study; and

\section{My Experience During the APE}

My preceptor, aware of my inexperience in this type of collaborative work, established a weekly meeting routine during office hours. Once per week, I met with Dr. Riley to discuss the

60 project and to review the weekly independent reading she assigned from a Community Based

61 Participatory Research (CBPR) textbook. As I did not have formal coursework on CBPR, it was

62 worthwhile to study CBPR concepts from an academic perspective prior to applying them in the

63 field. Our weekly sessions prepared me for our eventual in-person sessions with the community

64 group. For example, I was able to have my preceptor give me feedback on material I would be

65 presenting to the group, as well as receive help to organize my thoughts and ideas into a

66 structured meeting agenda.

67 The grant project offered up to $\$ 10,000$ in funding to support a CBPR project between an

68 academic and community partner to develop and maintain a mutually beneficial relationship. Our

69 next step was to identify how we could potentially use the grant funding to achieve our project 
goals. Our community partner CRC is a local group of artists, designers, researchers, educators,

71 and social workers working together to improve access to quality mental health care services.

72 Their goal was to design a program to help study alternative spaces where people seek mental

73 health relief.

The first meeting with our community partner CRC occurred early on in the process,

75 where different ideas where shared regarding possible avenues for development of an intervention. Our first goal for this project was to develop a formal letter of intent to deliver to

77 the selection committee regarding our plans to submit a full proposal for our project. Using

78 CRC's goals and vision as a framework for development, we decided to focus on immigrant and

79 refugee youth in the city of Philadelphia, a large and vulnerable population. Recognizing the

80 need for access to this population, we identified several other community partners as potential

81 collaborators, and worked independently to contact them and gauge their interest. After an

82 extensive outreach, we chose the group Southeast by Southeast (SExSE). This group already had

83 an established rapport with the immigrant and refugee community we were interested in, as well

84 as existing outreach programs to youth, offering us an opportunity to engage our desired

85 audience. After agreeing to the goals and objectives for the proposed project, we developed and

86 delivered a letter of intent to the grant committee, and shortly after received an invitation for a

87 full proposal.

Over the next few weeks, we developed the proposal from guidelines provided by the

89 CDRD committee through a series of meetings and conference calls. One of the main items of

90 the proposal was the budget. In collaboration with the university, SExSE, and CRC, we

91 developed our intervention program using assets from each group. Using known prices of

92 products and services as well as estimations of anticipated expenditures, we developed a list of 
93 expected costs and delineated how our $\$ 10,000$ budget would be spent. We combined the budget

94 narrative with descriptions of the project, timelines, and our goals and objectives and submitted

95 the proposal to the CDRD committee for approval.

96 The program was designed to be offered to 14-15 refugee and immigrant teens over a

97 series of 8 after school workshops. During these sessions, the participants used creative artistic

98 design strategies such as photography, collage, mapping, and book making to explore the

99 following research objectives:

- Define and identify places, people, strategies, and barriers to care,

- Understand what makes a safe space or home,

- Understand what makes a safe and supportive person,

- Understand strategies of safety,

- Unwrap how teens are coming of age in a western culture that is different than nuclear family dynamics (e.g. western individuality, idea of code/language switching), and

- Identify sustainable strategies that community sites can use to make safe spaces more accessible

While developing this project, I was simultaneously enrolled in a program planning and

110 evaluation course. The coursework included a mock scenario requiring development of a

111 literature review, project proposal with a budget, and an evaluation process. I found this to be

112 very valuable in developing my understanding of the process at hand. While these mock

113 exercises provided a solid foundation, the experience of applying these concepts to the real-

114 world CRC project was most valuable in cementing my understanding. The simulation cannot 
115 substitute for real life experiences such as organizing meeting times, sharing developments,

116 utilizing technology, and communicating with team members from a variety of disciplines.

117 My role as a graduate student occasionally afforded me the opportunity to be an acting

118 liaison between the University and community partners. In instances where my faculty mentor

119 was unavailable during a project meeting, I was tasked with representing the university,

120 requiring me to take detailed notes and to provide a summary of the developments in our

121 process. My participation in the development of the letter of intent, project, and budget proposal

122 provided me with deliverables to demonstrate my contributions to the project as required by

123 CEPH.

124 Challenges and Successes

125 This APE experience provided me with my first opportunity to participate in a proposal

126 process. While many of the challenges were mitigated through preparation, I sometimes found

127 myself unsure of my scope as a student and my capability to participate in certain project tasks.

128 One of the biggest challenges encountered during this experience was learning to adapt concepts

129 from the academic environment to the actual interactions with group members. This is where the

130 important value of the faculty mentor became apparent, as I was able to receive real-time

131 guidance.

132 Assigned readings about the CBPR process from my faculty mentor laid a sturdy

133 foundation to expand upon with the real experience I would later gain working on the project

134 proposal. With this base, I was able to better articulate group goals, foster effective

135 communication between academic and community partners, and anticipate challenges in the

136 process. Having regular one-on-one meetings with my faculty mentor also ensured that I was 
137 able to stay on track for my learning goals, and offered me an opportunity to debrief and ask

138 questions in a comfortable learning environment.

139 Implications for Practice

140 The involvement in this APE demonstrated the large potential for learning and real life

141 experience a student can be exposed to by being involved early in a project development process.

142 The practice of designing a proposal, conceptualizing a project, and working with community

143 partners is a valuable hands on learning experience which cannot be comparably simulated in a

144 classroom setting. Students should have the opportunity to join faculty members at this early

145 stage, and be involved with the proposal process. Involvement in co-drafting a proposal, budget,

146 and communicating with different project members is an invaluable experience for a student,

147 providing him or her with directly translatable skill that can be further expanded. Regardless of

148 the ultimate success of a proposal to secure funding, student involvement provides for a

149 significant learning opportunity.

\section{References}

152 Council on Education for Public Health. (2016). Accreditation criteria. Retrieved from https://media.ceph.org/wp_assets/2016.Criteria.pdf

154 Israel, B. A., Schulz, A. J., Parker, E. A., \& Becker, A. B. (1998). Review of CommunityBased Research: Assessing Partnership Approaches to Improve Public Health. Annual Review of Public Health, 19(1), 173-202. doi:10.1146/annurev.publhealth.19.1.173

157 Jefferson College of Population Health. (2018). MPH Clerkship-Applied Practice Experience $158 \quad$ Handbook. Retrieved from 
https://www.jefferson.edu/content/dam/university/population-health/student resources/C-

$\underline{\text { APEHandbook10.31.2017WEB.pdf }}$

Tables

162 Table 1. Selected CEPH Public Health Competencies as Related to this APE

\section{Public Health Knowledge}

- Explain the social, political, and economic determinants of health and how they contribute to population health and health inequities

\section{Foundational Competencies}

- Select quantitative and qualitative data collection methods appropriate for a given public health context

- Assess population needs, assets, and capacities that affect communities' health

- Explain basic principles and tools of budget and resource management

- Select methods to evaluate public health programs

- Perform effectively on interprofessional teams 